\title{
Shear Bond Strength of Metal and Ceramic Brackets to Composite Using Single Bond and Universal Adhesives
}

\author{
Hoda Pouyanfar ${ }^{1}$, Amin Golshah ${ }^{2 *}$, Matin Shekarbeigi ${ }^{3}$ \\ ${ }^{1}$ Assistant Professor, Department of Restorative Dentistry, Kermanshah University of Medical Sciences, Kermanshah, Iran; \\ ${ }^{2}$ Assistant Professor, Department of Orthodontics Dentistry, Kermanshah University of Medical Sciences, Kermanshah, Iran; \\ ${ }^{3}$ Student Research Committee, Kermanshah University of Medical Sciences, Kermanshah, Iran
}

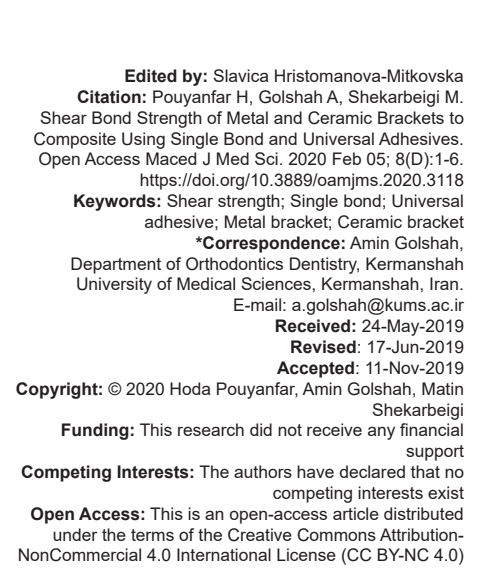

Abstract

AIM: This study aimed to assess the shear bond strength (SBS) of metal and ceramic brackets bonded to composite restorations using single bond $5^{\text {th }}$ generation bonding agent and G-Premio Bond universal adhesive.

MATERIALS AND METHODS: In this in vitro, experimental study, 60 sound extracted human premolars were veneered with composite and were then randomly divided into four groups $(n=15)$ of Single Bond + Transbond $\mathrm{XT}+$ metal brackets, universal adhesive + Transbond XT + metal brackets, Single Bond + Transbond XT + ceramic brackets, and universal adhesive + Transbond XT + ceramic brackets. Twenty-four hours after thermocycling, the SBS of brackets was measured using a universal testing machine. The adhesive remnant index (ARI) score was also determined under a stereomicroscope. Two-way ANOVA was used to compare the groups $(p<0.05)$

RESULTS: No significant difference was found in the mean SBS of ceramic and metal brackets or between the two bonding agents $(p>0.05)$. The interaction effect of type of bracket and type of bonding agent on SBS was not significant $(p>0.05)$. ARI score I had the highest frequency in Single Bond + Metal bracket group. The highest frequency of ARI score $V$ was noted in the Single Bond + Ceramic bracket group. A comparison of ARI scores of metal bracket groups showed a significant difference between single bond and universal adhesive $(p=0.002)$.

CONCLUSION: Both adhesives can provide adequate SBS for the bonding of metal and ceramic brackets to composite restorations.

\section{Introduction}

Leveled and aligned teeth play a fundamental role in smile esthetics and facial attractiveness. Due to the increased demand of adults for orthodontic treatment, orthodontic bracket bonding to dental restorations is now a common necessity [1]. Most adult orthodontic patients have several composite resin, amalgam, or ceramic restorations, and the brackets need to be bonded to restored surfaces [2]. Despite the advances in the bonding of orthodontic brackets to materials other than dental enamel, bracket bonding to dental restorations is still challenging for orthodontists [3],[4]. An acceptable bonding system should provide sufficiently high bond strength to prevent bracket debonding following the application of masticatory and orthodontic forces during the course of orthodontic treatment [5]. Thus, an efficient bonding agent should be used for the bonding of metal and ceramic brackets to restorative materials [6].

Several generations of bonding agents with different chemical compositions and variable procedural steps have been introduced to the market for the bonding of restorative materials to the dental substrate. The $5^{\text {th }}$ generation bonding agents are among the most commonly used bonding systems that include the application of an etchant and a bonding agent. The primer and bonding agents are supplied in one bottle in $5^{\text {th }}$ generation bonding systems [7].

Universal adhesives were recently introduced to the market with the ability to form a strong bond to the dental substrate and dental materials. They can be used in self-etch (one-step) and total-etch (two-step) modes [8],[9]. Universal adhesives are different from the $7^{\text {th }}$ generation bonding agents in that the universal adhesives are supplied in one single bottle and have different compositions of monomers [10],[11].

This study aimed to assess the shear bond strength (SBS) of metal and ceramic brackets bonded to composite surfaces using a $5^{\text {th }}$ generation bonding agent and a universal adhesive.

\section{Materials and Methods}

This in vitro, experimental study, evaluated 60 sound human premolars extracted for orthodontic 
treatment. The teeth were selected using convenience sampling. The study was approved by the ethics committee of Kermanshah University of Medical Sciences (IR.KUMS.REC.1396.418). The minimum sample size was calculated to be 13 in each group according to a study by Reddy et al. [12] assuming the standard deviation of SBS in ceramic and metal bracket groups to be 3.89 and 1.32 , respectively with the accuracy $(d)$ of 0.5 , alpha $=0.01$, and power of $95 \%$. To increase the accuracy of the results, 15 teeth were evaluated in each group.

The teeth were sound and were evaluated under a microscope to ensure the absence of caries and cracks. The teeth were disinfected using a $0.5 \%$ chloramine $\mathrm{T}$ solution for $24 \mathrm{~h}$ and were then immersed in distilled water. Next, they were mounted in auto-polymerizing acrylic resin (Acropars, Tehran, Iran) and were divided into four groups of 15. The buccal surface of each tooth was etched with $37 \%$ phosphoric acid (Vivadent, USA) for $20 \mathrm{~s}$, rinsed for $10 \mathrm{~s}$ and dried with air spray for $10 \mathrm{~s}$. Single Bond (3M ESPE, St. Paul, MN, USA) was applied on the surface and light-cured with a LED curing unit (Wood Pecker, Muenster, Germany) with a light intensity of $150 \mathrm{mw} / \mathrm{cm}^{2}$ for $10 \mathrm{~s}$. Two 1-mm-thick increments of Z350 composite (3M ESPE, St. Paul, MN, USA) were applied to cover the labial surface of the teeth and lightcured for $20 \mathrm{~s}$. The teeth were then incubated for $48 \mathrm{~h}$. Tooth surfaces were then etched with $37 \%$ phosphoric acid for $15 \mathrm{~s}$ and subjected to the following procedures:

Group 1: Single Bond $5^{\text {th }}$ generation bonding agent (3M ESPE, St. Paul, MN, USA) was applied in two coats and mildly air-sprayed for $5 \mathrm{~s}$. Curing was performed for $10 \mathrm{~s}$ using a LED curing unit. Transbond XT composite was then applied on the surface for bonding of metal brackets (Focus, G \& H Orthodontics, USA), and light-cured for $20 \mathrm{~s}$.

Group 2: G-Premio Bond universal adhesive (GC, Tokyo, Japan) $8^{\text {th }}$ generation bonding agent was applied on the surface in two coats, thinned with gentle air spray for $5 \mathrm{~s}$ and light-cured for $10 \mathrm{~s}$. Metal brackets were bonded with Transbond XT composite, and lightcuring was performed for $20 \mathrm{~s}$.

Group 3: Single bond was applied in two coats and mildly air sprayed for $5 \mathrm{~s}$. Curing was performed for $10 \mathrm{~s}$. Transbond XT composite was then applied on the surface for bonding of ceramic brackets (Identification, $\mathrm{G}$ and $\mathrm{H}$ Orthodontics, USA) and light-cured for $20 \mathrm{~s}$.

Group 4: G-Premio Bond universal adhesive was applied on the surface in two coats, thinned with gentle air spray for $5 \mathrm{~s}$ and light-cured for $10 \mathrm{~s}$. Ceramic brackets were bonded with Transbond XT composite, and light-curing was performed for $20 \mathrm{~s}$.

The teeth in each group were mounted in acrylic resin perpendicular to the horizon and parallel to each other. Samples in each group were immersed in distilled water and incubated at $37^{\circ} \mathrm{C}$ and $100 \%$ humidity for $24 \mathrm{~h}$. The samples were then thermocycled between $5^{\circ} \mathrm{C}$ and $55^{\circ} \mathrm{C}$ for $48 \mathrm{~h}$ with a dwell time of $20 \mathrm{~s}$ and a transfer time of $10 \mathrm{~s}$. The teeth were then sectioned into $1 \mathrm{~mm}$ thick slices using a Mecatome (Presi, France), and the slices were transferred to a universal testing machine (Zwick Roell, Ulm, Germany). Samples were fixed in the universal testing machine with cyanoacrylate glue such that the composite-tooth interface was parallel to the two horizontal plates and was located at the mid-point between them. The load was applied at a crosshead speed of $0.5 \mathrm{~mm} / \mathrm{min}$, and the maximum load at failure was recorded.

The surface area of the debonded interface was measured using a gauge. The maximum load at failure in newtons was divided by the enamel/composite and composite/bracket interface surface area by squaremillimeters $\left(\mathrm{mm}^{2}\right)$ to calculate the SBS in megapascals (MPa). The ARI score was also determined under a stereomicroscope at $\times 20$ (Italy) and was categorized into five types according to the amount of composite remaining on the tooth surface as follows [13]:

Type I: The entire composite remained on the tooth surface.

Type II: More than $90 \%$ of composite remained on the tooth surface.

Type III: Between $10 \%$ and $90 \%$ of composite remained on the tooth surface.

Type IV: Less than $10 \%$ of composite remained on the tooth surface.

Type V: No composite remained on the tooth surface.

Data were analyzed using SPSS version 18

(SPSS Inc., IL, USA). Normal distribution of data was evaluated using the Kolmogorov-Smirnov test, which showed that data were normally distributed $(p=0.1)$. Thus, two-way ANOVA was applied to assess the effect of type of bracket (metal or ceramic) and type of bonding agent (Single Bond or universal adhesive) on SBS (peak and breaking point). The Mann-Whitney $U$-test was used to compare the groups in terms of ARI scores. The Tukey's test was applied for pairwise comparisons. The level of significance was set at 0.05 .

\section{Results}

Table 1 shows the mean SBS of the groups at the breaking point. The highest SBS at the breaking point was noted in Single Bond + ceramic bracket group. Two-way ANOVA showed no significant difference in the mean SBS of metal and ceramic brackets at the breaking point $(p=0.246)$. No significant difference was

Table 1: Mean SBS of the groups at the breaking point

\begin{tabular}{|c|c|c|c|c|c|}
\hline \multirow[t]{3}{*}{ Bracket } & \multicolumn{4}{|c|}{ Bonding agent } & \multirow[t]{3}{*}{$p$-value } \\
\hline & \multicolumn{2}{|c|}{ Single bond } & \multicolumn{2}{|c|}{ Universal adhesive } & \\
\hline & Mean & SD & Mean & SD & \\
\hline Metal & 8.46 & 5.25 & 6.07 & 4.23 & 0.345 \\
\hline Ceramic & 9.82 & 10.59 & 8.98 & 6.40 & \\
\hline $\mathrm{p}$-value & 0.378 & & & & \\
\hline
\end{tabular}


noted in SBS of single bond and universal adhesive at the breaking point either $(p=0.378)$. The interaction effect of the type of bracket and type of bonding agent on SBS was not significant $(p=0.671)$.

Table 2 shows the mean peak SBS of the groups. The highest peak SBS belonged to Single Bond + metal bracket group. Two-way ANOVA showed no significant difference in peak SBS of ceramic and

Table 2: Mean peak SBS of the groups

\begin{tabular}{llllll}
\hline Bracket & \multicolumn{2}{l}{ Bonding agent } & & p-value \\
\cline { 2 - 4 } & \multicolumn{2}{l}{ Single bond } & Universal adhesive & \\
\cline { 2 - 4 } & Mean & SD & Mean & SD & \\
\hline Metal & 10.65 & 3.71 & 6.57 & 4.14 & 0.345 \\
Ceramic & 10.55 & 10.14 & 9.79 & 5.75 & \\
p-value & 0.153 & & & &
\end{tabular}

metal brackets $(p=0.345)$. The difference in peak SBS between single bond and universal adhesive was not significant either $(p=0.153)$. The interaction effect of type of bracket and type of bonding agent on peak SBS was not significant either $(p=0.324)$.

Table 3 shows the ARI scores in the four groups. The highest frequency of ARI score I $(n=11)$ was noted in Single Bond + Metal bracket group. The highest frequency of ARI score $V(n=7)$ was noted in Single Bond + Ceramic bracket group.

Comparison of ARI scores of metal brackets between single bond and universal adhesive groups showed a significant difference $(p=0.002)$ such that the median of ARI scores in use of single bond was lower than that in use of universal adhesive. This difference was not significant for the ceramic brackets $(p=0.519)$.

A comparison of metal and ceramic brackets in terms of ARI scores revealed no significant difference between them in the use of single bond $(p=0.077)$. The difference in this regard between metal and ceramic brackets in the use of universal adhesive was not significant either $(p=0.167)$.

\section{Discussion}

Optimal bracket bond strength must prevent debonding during the course of treatment and should not damage the enamel surface in the process of debonding following completion of orthodontic treatment [14],[15]. This study assessed the SBS of metal and ceramic brackets bonded to composite restorations using a single bond $5^{\text {th }}$ generation bonding agent and a universal adhesive. The results showed no significant difference in the mean SBS of ceramic and metal brackets or between the two bonding agents. The interaction effect of type of bracket and type of bonding agent on SBS was not significant either.

Composite resin is commonly used for orthodontic bracket bonding to enamel following acid etching of the enamel surface [16]. Toledano et al. [17] measured the SBS of orthodontic brackets bonded with different cements and concluded that the use of lightcure composite resin yielded the highest bond strength. Joseph and Rossouw [18] showed that light-cure composite is suitable for bonding of stainless steel and ceramic brackets to teeth. Thus, Transbond XT was used for bracket bonding in our study.

In the current study, the highest SBS at the breaking point belonged to Single Bond + ceramic bracket group while the lowest SBS was noted in universal adhesive + metal bracket group. Reynolds and Fraunhofer [19] stated that the minimum required bond strength for bracket bonding to enamel is 5.9-7.8 MPa while this value was reported to be $7 \mathrm{MPa}$ by Lopez [20]. Endo et al. [21], and Pannes et al. [22] reported that the clinically acceptable SBS ranges from 6 to $8 \mathrm{MPa}$. Humberto et al. [23] reported the ideal bond strength value to be 6-10 MPa. Fuhrmann et al. [24] demonstrated that the clinical bond strength should be as high as 5-8 MPa. Our findings revealed that the SBS values obtained in all four groups in our study were within the clinically acceptable range according to the above-mentioned studies although the combination of single bond and ceramic bracket yielded higher SBS at the breaking point $(10.59 \pm 9.82 \mathrm{MPa})$.

Single bond $5^{\text {th }}$ generation bonding agent is composed of bisphenol glycidyl methacrylate (bis-GMA), hydroxyethyl methacrylate, dimethacrylate polyalkenoic acid copolymer, initiator, water, and ethanol [25]. Bis-GMA has no chemical affinity for metals or dental substrate, and its bonding mechanism is based on mechanical interlocking. If bis-GMA derivatives can better wet the oxide-coated surface of attachments (which are both polar) and penetrate into the surface, the bond strength would increase [26]. Cavalcante et al. [27] reported that the SBS of single bond in total-etch mode was higher than that of Clearfil Liner Bond 2V used in self-etch mode. Perdigao et al. [28] reported that single bond (3M) yielded the highest bond strength to dentin and enamel. Yazici et al. [29] reported that single bond (3M)

Table 3: Adhesive remnant index score in the four groups

\begin{tabular}{|c|c|c|c|c|c|c|c|c|c|c|}
\hline \multirow[t]{3}{*}{ Group } & \multicolumn{10}{|l|}{ ARI } \\
\hline & \multicolumn{2}{|l|}{$\mathrm{I}$} & \multicolumn{2}{|l|}{ II } & \multicolumn{2}{|l|}{ III } & \multicolumn{2}{|l|}{ IV } & \multicolumn{2}{|l|}{$\mathrm{V}$} \\
\hline & Count & Percentage & Count & Percentage & Count & Percentage & Count & Percentage & Count & Percentage \\
\hline Single bond and metal bracket & 11 & 73.3 & 2 & 13.3 & 2 & 13.3 & 0 & 0 & 0 & 0 \\
\hline Single bond and ceramic bracket & 8 & 53.3 & 0 & 0 & 0 & 0 & 0 & 0 & 7 & 46.7 \\
\hline Universal adhesive and metal bracket & 2 & 13.3 & 7 & 46.7 & 3 & 20.0 & 0 & 0 & 3 & 20.0 \\
\hline Universal adhesive and ceramic bracket & 8 & 53.3 & 2 & 13.3 & 2 & 13.3 & 0 & 0 & 3 & 20.0 \\
\hline
\end{tabular}

Universal adhesive and ceramic bracket

ARI: Adhesive remnant index. 
yielded the highest bond strength to the enamel. Isolan et al. [30] showed that the highest and the lowest bond strength values were provided by the use of Single Bond (3M) and Single Bond Universal, respectively. Metal brackets require mechanical retention for bonding, and their mesh structure serves this purpose [31]. Primary reports regarding the bond strength of ceramic brackets with chemical retention indicated a strong bond higher than the optimal value for bracket debonding, which could result in enamel damage [32]. Thus, ceramic brackets with mechanical retention were introduced to decrease the risk of enamel damage in the process of debonding [33]. By creating mechanical retention, the entire pressure applied for debonding is directed to the bracket-resin interface, while in the presence of chemical retention, the load for debonding is applied to the enamel-resin interface [17]. Bishara et al. [34], Sinha et al. [35], and Arici et al. [36] also confirmed this finding and did not notice enamel damage following the debonding of ceramic brackets with mechanical retention. However, some reports regarding enamel fracture following the debonding of these ceramic brackets are available [32],[37]. This controversy can be due to different mechanisms of bracket retention, method of debonding, and type of adhesive used [38].

Debonding may occur at the bracket-adhesive interface, within the adhesive, or at the enameladhesive interface. Ideally, bond failure should occur at the bracket-adhesive interface in order not to damage the enamel surface (although the time spent for ARI). Evidence shows that the interface between the adhesive and bracket base is the weakest point for debonding [39]. As the bond strength increases, the debonding interface moves toward the enamel-adhesive interface, and greater pressure is applied to the enamel. Thus, the risk of enamel cracks following debonding increases, which would cause patient dissatisfaction and the need for tooth restoration [34],[35]. In the current study, the results showed that ARI score I (entire composite remaining on the tooth surface) had the highest frequency in the use of single bond and metal bracket. ARI score $V$ (absence of composite remnants on the tooth surface) had the highest frequency in the use of single bond and ceramic bracket. These results can be interpreted by taking into account the bond strength values such that as the bond strength increased, the debonding location approximated the enamel and distanced from the bracket. A comparison of ARI scores in the use of metal brackets showed a significant difference between single bond and universal adhesive bonding agents. A comparison of ARI scores in the use of ceramic brackets showed no significant difference between the two bonding agents. In the use of single bond and universal adhesive, no significant difference was noted in ARI scores between metal and ceramic brackets. Romano et al. [40] used Transbond XT composite and reported the highest frequency of debonding at the adhesive-bracket interface while by the use of Z100 and Concise composites, debonding occurred at the adhesive-enamel interface. Fernandez and Canut [32] in their in vitro study bonded ceramic, metal, and plastic brackets to bovine enamel using diacrylate resin and showed the highest bond strength for metal and the lowest for plastic brackets. Reynods and Fraunhofer [19] stated that the SBS should not exceed $14 \mathrm{MPa}$ because it would damage the enamel or the bonding surface. In our study, the SBS in the four groups did not exceed this threshold. Woolaver [41] discussed that enamel fracture may occur with the minimum bond strength of $13.5 \mathrm{MPa}$. Although low bond strength is a shortcoming of using metal brackets, it can be a relative advantage in the use of ceramic brackets because high bond strength of adhesives to ceramic brackets is considered a drawback since it would damage the enamel during debonding [42].

This study had an in vitro design. Therefore, the generalization of results to the clinical condition must be done with caution.

\section{Conclusion}

The mean SBS of all four groups was within the acceptable range, with no significant difference among them. Thus, both single bond and G-Premio Bond universal adhesive provide adequately high (but not too high) bond strength for bonding of metal and ceramic brackets to composite restorations.

\section{References}

1. Türkkahraman $H$, Küçükesmen $H C$. Porcelain surfaceconditioning techniques and the shear bond strength of ceramic brackets. Eur J Orthod. 2006;28(5):440-3. https://doi. org/10.1093/ejo/cjl026

PMid:16916898

2. Stella JP, Oliveira AB, Nojima LI, Marquezan M. Four chemical methods of porcelain conditioning and their influence over bond strength and surface integrity. Dent Press J Orthod. 2015;20(4):51-6. https://doi.org/10.1590/2176-9451.20.4.051056.oar

PMid:26352845

3. Huang $\mathrm{TH}, \mathrm{Kao} \mathrm{CT}$. The shear bond strength of composite brackets on porcelain teeth. Eur J Orthod. 2001;23(4):433-9. PMid:11544794

4. Trakyali G, Malkondu O, Kazazoğlu E, Arun T. Effects of different silanes and acid concentrations on bond strength of brackets to porcelain surfaces. Eur J Orthod. 2009;31(4):402-6. https://doi. org/10.1093/ejo/cjn118 PMid:19339674

5. Akova T, Yoldas O, Toroglu MS, Uysal H. Porcelain surface treatment by laser for bracket-porcelain bonding. Am J Orthod Dentofacial Orthop. 2005;128(5):630-7. https://doi. org/10.1016/j.ajodo.2004.02.021 


\section{PMid: 16286211}

6. Schmage P, Nergiz I, Herrmann W, Ozcan M. Influence of various surface-conditioning methods on the bond strength of metal brackets to ceramic surfaces. Am J Orthod Dentofacial Orthop. 2003;123(5):540-6. https://doi.org/10.1067/mod.2003. s0889540602569110

PMid:12750673

7. Summitt JB, Robbins JW, Hilton TJ, Schwartz RS. Fundamentals of Operative Dentistry: A Contemporary Approach. USA: Quintessence Publishing; 2006.

8. Loguercio AD, Muñoz MA, Luque-Martinez I, Hass V, Reis A, Perdigão J. Does active application of universal adhesives to enamel in self-etch mode improve their performance? J Dent. 2015;43(9):1060-70. https://doi.org/10.1016/j.jdent.2015.04.005 PMid:25908573

9. Alex G. Universal adhesives: The next evolution in adhesive dentistry? Compend Contin Educ Dent. 2015;36(1):15-26. PMid:25822403

10. Muñoz MA, Luque-Martinez I, Malaquias $P$, Hass $V$, Reis $A$, Campanha $\mathrm{NH}$, et al. In vitro longevity of bonding properties of universal adhesives to dentin. Oper Dent. 2015;4(3):282-92. https://doi.org/10.2341/14-055-I

\section{PMid:25405904}

11. Luque-Martinez IV, Perdigão J, Muñoz MA, Sezinando A Reis A, Loguercio AD. Effects of solvent evaporation time on immediate adhesive properties of universal adhesives to dentin. Dent Mater. 2014;30(10):1126-35. https://doi.org/10.1016/j. dental.2014.07.002

PMid:25139815

12. Reddy YG, Sharma R, Singh A, Agrawal V, Agrawal V, Chaturvedi $\mathrm{S}$. The shear bond strengths of metal and ceramic brackets: An in-vitro comparative study. J Clin Diagn Res. 2013;7(7):1495-7.

PMid:23998105

13. Oliver RG, Pal AD. Distortion of edgewise orthodontic brackets associated with different methods of debonding. Am J Orthod Dentofacial Orthop. 1989;96(1):65-71. https://doi. org/10.1016/0889-5406(89)90231-x PMid:2665474

14. van Waveren Hogervorst WL, Feilzer AJ, Prahl-Andersen B. The air-abrasion technique versus the conventional acidetching technique: A quantification of surface enamel loss and a comparison of shear bond strength. Am J Orthod Dentofacial Orthop. 2000;117(1):20-6. https://doi.org/10.1016/ s0889-5406(00)70244-7

PMid:10629516

15. Olsen ME, Bishara SE, Damon P, Jakobsen JR. Evaluation of Scotchbond multipurpose and maleic acid as alternative methods of bonding orthodontic brackets. Am J Orthod Dentofacial Orthop. 1997;111(5):498-501. https://doi. org/10.1016/s0889-5406(97)70286-5 PMid:9155808

16. Buyuk SK, Cantekin K, Demirbuga S, Ali Ozturk M. Are the low-shrinking composites suitable for orthodontic bracket bonding? Eur J Dent. 2013;7(3):284-8. https://doi. org/10.4103/1305-7456.115411

PMid:24926207

17. Toledano M, Osorio R, Osorio E, Romeo A, de la Higuera B, García-Godoy F. Bond strength of orthodontic brackets using different light and self-curing cements. Angle Orthod. 2003;73(1):56-63.

PMid:12607856

18. Joseph VP, Rossouw E. The shear bond strengths of stainless steel and ceramic brackets used with chemically and light-activated composite resins. Am J
Orthod Dentofacial Orthop. 1990;97(2):121-5. https://doi. org/10.1016/0889-5406(90)70084-p

PMid:2137284

19. Reynolds IR, von Fraunhofer JA. Direct bonding of orthodontic attachments to teeth: The relation of adhesive bond strength to gauze mesh size. Br J Orthod. 1976;3(2):91-5. https://doi. org/10.1179/bjo.3.2.91

PMid:779822

20. Lopez JI. Retentive shear strengths of various bonding attachment bases. Am J Orthod. 1980;77(6):669-78. https://doi. org/10.1016/0002-9416(80)90158-x

PMid:6992590

21. Endo T, Ozoe R, Shinkai K, Shimomura J, Katoh Y, Shimooka S. Comparison of shear bond strengths of orthodontic brackets bonded to deciduous and permanent teeth. Am J Orthod Dentofacial Orthop. 2008;134(2):198-202. https://doi. org/10.1016/j.ajodo.2006.05.045 PMid: 18675200

22. Pannes DD, Bailey DK, Thompson JY, Pietz DM. Orthodontic bonding to porcelain: A comparison of bonding systems. J Prosthet Dent. 2003;89(1):66-9. https://doi.org/10.1067/ mpr.2003.63 PMid:12589289

23. Barceló Santana HF, Hernández Medina R, Acosta Torres SL, Sánchez Herrera LM, Fernández Pedrero AJ, Ortíz González R. Evaluation of bond strength of metal brackets by a resin to ceramic surfaces. J Clin Dent. 2006;17(1):5-9.

PMid:16838874

24. Fuhrmann R, Gutknecht N, Magunski A, Lampert F, Diedrich $P$. Conditioning of enamel with $\mathrm{Nd}$ : YAG and $\mathrm{CO}_{2}$ dental laser systems and with phosphoric acid. An in-vitro comparison of the tensile bond strength and the morphology of the enamel surface. J Orofac Orthop. 2001;62(5):375-86. https://doi.org/10.1007/ pl00001943

PMid:11590826

25. Perdigao J, Swift E, Walter R. Fundamental concepts of enamel and dentin adhesion. In: Sturdevant's Art and Science of Operative Dentistry. London, United Kingdom: Elsevier Health Sciences; 2014. p. 114-40. https://doi.org/10.1016/ b978-0-323-47833-5.00005-8

26. Matasa C. Do adhesives and sealants really seal the brackets' pad? II. surface tension. Orthod Mat Insider. 2003;15:4-8.

27. Cavalcante LM, Erhardt MC, Bedran-de-Castro AK, Pimenta LA, Ambrosano GM. Influence of different tests used to measure the bond strength to dentin of two adhesive systems. Am J Dent. 2006;19(1):37-40.

PMid: 16555656

28. Perdigão J, Gomes G, Gondo R, Fundingsland JW. In vitro bonding performance of all-in-one adhesives. Part I microtensile bond strengths. J Adhes Dent. 2006;8(6):367-73 PMid: 17243593

29. Yazici AR, Celik C, Ozgünaltay G, Dayangaç B. Bond strength of different adhesive systems to dental hard tissues. Oper Dent. 2007;32(2):166-72. https://doi.org/10.2341/06-49

PMid: 17427826

30. Isolan CP, Valente LL, Münchow EA, Basso GR, Pimentel AH, Schwantz JK, et al. Bond strength of a universal bonding agent and other contemporary dental adhesives applied on enamel dentin composite and porcelain. Appl Adhes Sci. 2014;2:25-33. https://doi.org/10.1186/s40563-014-0025-x

31. Keim RG, Gottlieb EL, Nelson AH, Vogels DS $3^{\text {rd }}$. 2008 JCO study of orthodontic diagnosis and treatment procedures. Part 3: More breakdowns of selected variables. J Clin Orthod. 2009;43(1):22-33.

PMid: 19276571 
32. Fernandez L, Canut JA. In vitro comparison of the retention capacity of new aesthetic brackets. Eur $\mathrm{J}$ Orthod. 1999;21(1):71-7.

PMid: 10191580

33. Bishara SE, Fehr DE. Ceramic brackets: Something old, something new, a review. Semin Orthod. 1997;3(3):178-88. https://doi.org/10.1016/s1073-8746(97)80068-0

PMid:9573879

34. Bishara SE, Fehr DE, Jakobsen JR. A comparative study of the debonding strengths of different ceramic brackets, enamel conditioners, and adhesives. Am J Orthod Dentofacial Orthop. 1993;104(2):170-9. https://doi.org/10.1016/s0889-5406 (05)81007-8

PMid:8338070

35. Sinha PK, Nanda RS. The effect of different bonding and debonding techniques on debonding ceramic orthodontic brackets. Am J Orthod Dentofacial Orthop. 1997;112(2):132-7. https://doi.org/10.1016/s0889-5406(97)70237-3 PMid:9267223

36. Arici $\mathrm{S}$, Minors $\mathrm{C}$. The force levels required to mechanically debond ceramic brackets: An in vitro comparative study. Eur J Orthod. 2000;22(3):327-34. https://doi.org/10.1093/ejo/22.3.327 PMid:10920565

37. Blalock KA, Powers JM. Retention capacity of the bracket bases of new esthetic orthodontic brackets. Am J Orthod Dentofacial Orthop. 1995;107(6):596-603. https://doi.org/10.1016/s08895406 (95)70102-8

PMid: 7771364

38. Bishara SE. Ceramic brackets and the need to develop national standards. Am J Orthod Dentofacial Orthop. 2000;117:595-7. PMid:10799127

39. Ireland AJ, Sherriff M. Use of an adhesive resin for bonding orthodontic brackets. Eur J Orthod. 1994;16(1):27-34. https:// doi.org/10.1093/ejo/16.1.27 PMid:8181547

40. Romano FL, Tavares SW, Nouer DF, Consani S, Borges de Araújo Magnani MB. Shear bond strength of metallic orthodontic brackets bonded to enamel prepared with self-etching primer. Angle Orthod. 2005;75(5):849-53.

PMid:16285044

41. Woolaver CJ. The Shear/Peel Bond Strengths of Orthodontic Attachments to Composite Resin; 2001. Available from: http:// www.hdl.handle.net/1993/19554.

42. Jost-Brinkmann PG, Can S, Drost C. In-vitro study of the adhesive strengths of brackets on metals, ceramic and composite. Part 2: Bonding to porcelain and composite resin. J Orofac Orthop. 1996;57(3):132-41.

PMid:8655108 